\begin{tabular}{|c|c|c|}
\hline $\begin{array}{l}\text { INESEG } \\
\text { INTERNATIONAL } \\
\text { ENGINEERING } \\
\text { SCIENCE AND } \\
\text { EDUCATION GROUP }\end{array}$ & $\begin{array}{l}\text { International Journal of Health Services } \\
\text { Research and Policy } \\
\text { www.dergipark.org.tr/ijhsrp } \\
\text { e-ISSN: } 2602-3482\end{array}$ & IJHSRP \\
\hline
\end{tabular}

Research Article

\title{
FREQUENCY AND POWER ANALYSIS OF EEG THETA ACTIVITY DURING DIFFERENT NUMERICAL AND VERBAL TASK IN MALES
}

\author{
Mehmet Cihan YAVAŞ ${ }^{* 1}[$ \\ ${ }^{1}$ Kırşehir Ahi Evran University, Faculty of Medicine, Department of Biophysics, Kırşehir, Turkey, \\ Corresponding author; mcihanyavas@ahievran.edu.tr
}

\begin{abstract}
The brain forms EEG waves due to mental processes. This study aims to investigate the effectiveness of the EEG theta wave formed in the brain during different numerical and verbal tasks. Twenty healthy medical male students without any health problems were included in the study. The five questions were answered by the subjects via PowerPoint on the computer screen. Bipolar electrode positioning was performed. In this study, domain measurements, FFT, and power spectral density were analyzed. As a result of the study, no statistically significant difference was found between EEG theta waves obtained as a result of both numerical and verbal correct and incorrect answers ( $p>0.05)$. An increase in mean amplitude was found in both the numerical and verbal processes to respond incorrectly. As a result, no significant change was observed in the domain measurements, frequency, and power analysis of EEG theta waves during numerical and verbal correct and incorrect responses.
\end{abstract} Keywords: Theta, FFT, PSD, mental, verbal, numerical

Received: April 24, $2020 \quad$ Accepted: June 17,2020

\section{Introduction}

EEG is used to measure the functional state and electrical activity of the brain. Different brain waves accompany the rhythmic activity of the brain. In particular, the theta wave shows activity in the frequency range 4-7 Hz. Theta wave does not affect phase I of sleep but also in working memory, mental effort, short-term memory loadings, and cognitive events [1]. EEG measures neurobiological studies that occur in mental processes, resting states, and cognitive processes and directly measures the electrical activity of the brain [2]. It is known that the analysis of human EEG during various motor and image tasks is useful for evaluating the links between nervous system functions and behaviors and provides a simple measure of neural activity in real-time. The EEG is captured using wired sensors connected to specific locations along with the head [3]. Due to its non-invasive nature, EEG detection is widely used in many areas such as neurophysiology, psychology, pathophysiology, cognitive neuroscience, neuroengineering, and even social psychology. Also, many studies have interpreted the relationship between specific mental states and EEG [4]. In the process of working memory, an increase in theta activity is observed, and a decline in memory working decreases the activity of the theta wave [5]. However, in 
some studies, in the process of difficult mathematical tasks, the degree of difficulty of the mathematical problem can be discussed, it is reported that there is no significant change in theta wave [6].

In our study, we established the hypothesis that there is a change in the theta wave between different numerical and verbal processes. In this study, we investigated the changes in the parameters of Fast Fourier Transformation (FFT), Power Spectral Density (PSD), and domain measurements of theta wave in mental processes.

\section{Materials and Methods}

The subjects included in the study declared that they are healthy and have no disease. Therefore, they do not include any neurological disorders, smoking status, and medical drug consumption, and other disease groups. 20 healthy medical male students with no health problems were included in the study. The average age is $21.15 \pm 2.10$ years. The study was started after the consent of all subjects.

Ethical Procedure: Kursehir Ahi Evran University Faculty of Medicine Clinical Research Ethics Committee decision was taken (2019-07/85). The experiment was carried out according to the Declaration of Helsinki.

\subsection{Experimental procedure and EEG data acquisition}

All subjects continued for 10 seconds for numerical and 10 seconds for verbal procedures. Biopac sterile disposable electrodes lead set (EL503) were placed on the left side of the skull. The earth electrode was placed under the ear. Using Biopac MP36 Student Lab software version 4.1 (BIOPAC System Inc., Goleta, CA, USA), analysis of the raw EEG waves for the theta wave was performed.

In this study, mental procedures were performed with two different methods. The average response was 5 seconds for 10 missions. Method 1: numerical correct questions; a) $9 X 2=18$, b) 35/7 = 5 , c) $108+3=111$, d) $57-8=49$. Numerical incorrect operations; a) $9 X 2=16$, b) $35 / 7=8$, c) $108+3=$ 1111 , d) $57-8=41$.

Method 2: Verbal correct questions; a) Turkey's capital? = Ankara, b) Who is the president of the United States? = Trump c) What is the name of the college you're studying? = Kırşehir Ahi Evran University, d) What will your profession be when you graduate from this department? = Doctor.

Verbal incorrect operations; a) Turkey's capital? = Istanbul, b) Who is the US's president = Obama, c) What is the name of the university where you are studying? = Ankara University, d) What profession will you do after graduating from this university? = Engineer.

This study was carried out at Kırşehir Ahi Evran University. The Biopac MP36 student experiment system was used for recording with bipolar electrodes. The electrodes were placed on the left side of the head. Domain measurements, FFT, and PSD measurements of EEG theta signals were measured during mental procedures from all subjects. Figure 1 shows the experimental design, figure 2 shows the FFT analysis, figure 3 shows the PSD analysis, and figure 4 shows the raw EEG analysis. 


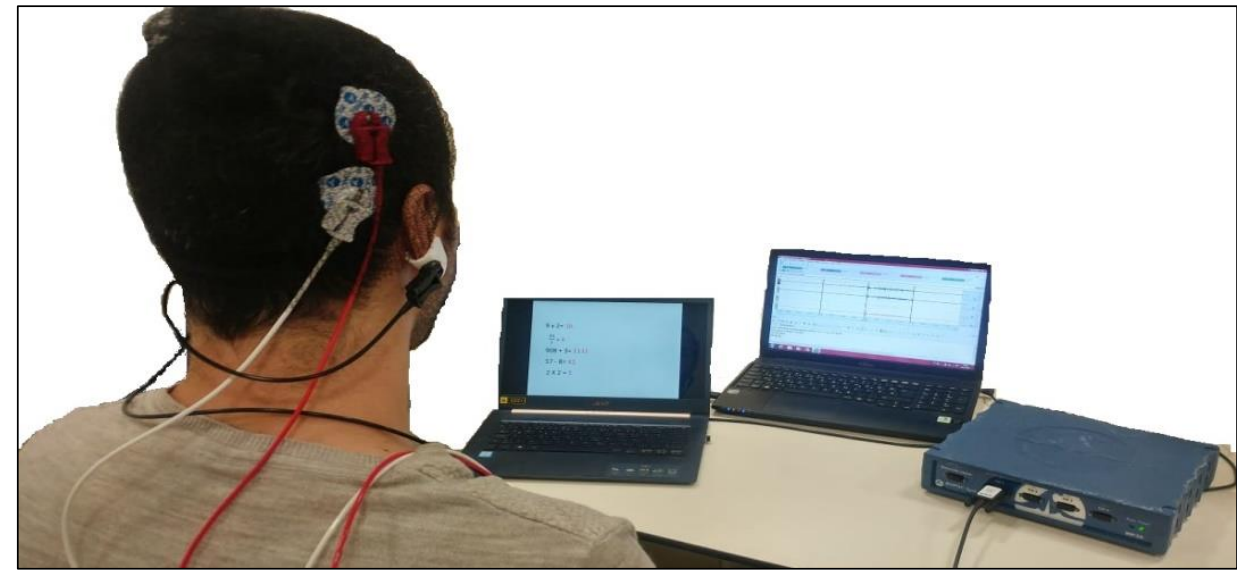

Figure 1. Experimental design

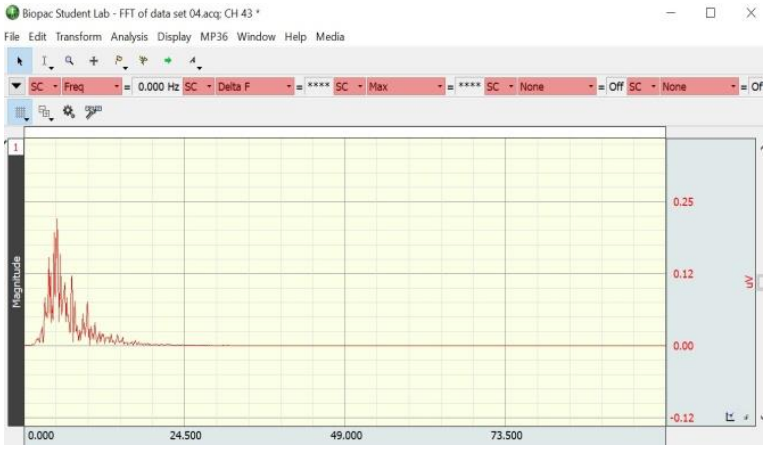

Figure 2. FFT analysis example

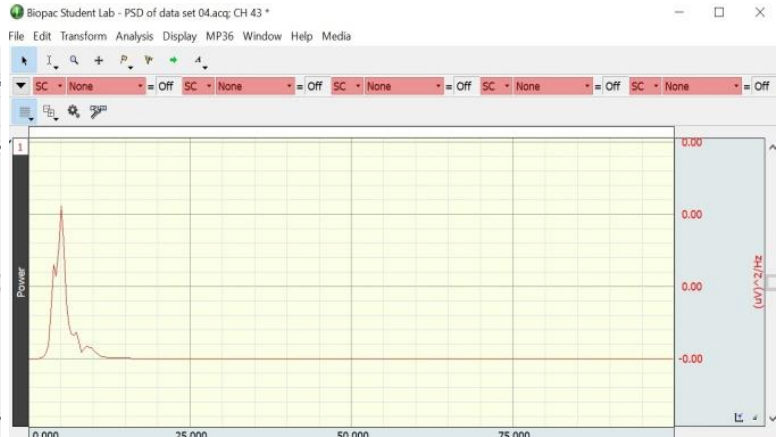

Figure 3. PSD analysis example

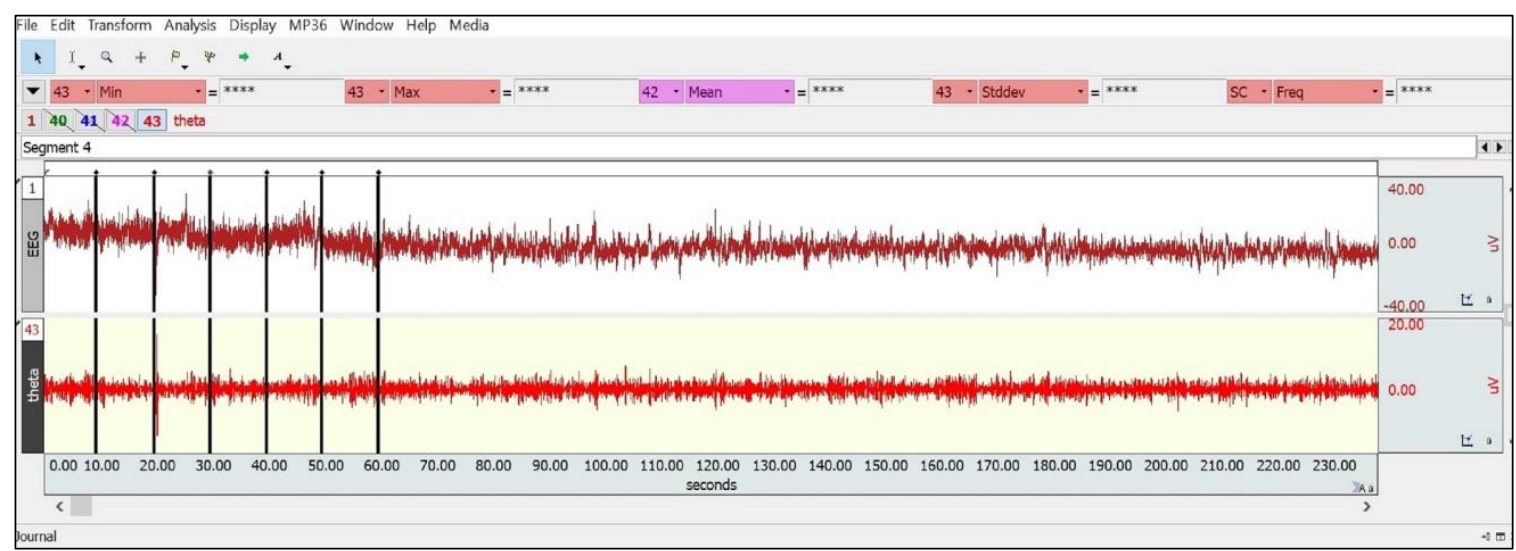

Figure 4. EEG raw data analysis and theta wave

\subsection{Data Analysis}

The normality hypothesis was tested by the Kolmogorov-Smirnov and the Shapiro-Wilk tests. Descriptive statistics of the variables are given as Mean \pm Standart deviation, Median (25th percentile 75th percentile). Paired t-test and Wilcoxon matched-pair test were used for univariate analysis of dependent variables. Statistical analysis of the study was performed by using Statistical Package for Social Sciences version 21.0 software for Windows (V.21.0. Armonk, NY: IBM Corp., USA). 


\section{Results}

In this study, 3 electrodes were placed on the left side of the subjects as shown in Figure 1. The analysis was performed with the help of two computers. Mental tasks were monitored in one computer and the EEG record was measured on the other computer. In our study, time-based field measurements were taken. These are shown in Table 1 and Table 2. Min: The minimum measurement finds the minimum amplitude value within the selected area. Max: The maximum measurement finds the maximum amplitude value within the selected area. Mean: The mean measurement computes the mean amplitude value. Std: Standard deviation is a measure of the variability of data points. Skew: Skew is a statistical measure of the degree of asymmetry in a distribution. The normal distribution has a skew of 0 . The left tail has a negative skew, the right tail has a positive skew. Kurtosis: It indicates the degree of peaknedness in distribution, e.g. the size of the "tails" of the distribution. Lin reg: It is a better method to calculate the slope when you have noisy, erratic data [7].

Table 1. Domain measurements (Mean parameter results for 20 subjects)

\begin{tabular}{|c|c|c|c|c|c|c|c|c|c|c|}
\hline $\begin{array}{c}\text { Mean } \\
(\mu \mathrm{V})\end{array}$ & $\begin{array}{l}\text { Min } \\
(\mu \mathrm{V})\end{array}$ & $\begin{array}{l}\text { Max } \\
(\mu \mathrm{V})\end{array}$ & $\begin{array}{l}\text { Std } \\
\text { dev } \\
(\mu \mathrm{V})\end{array}$ & $\begin{array}{c}\text { Skew } \\
(\mu \mathrm{V})\end{array}$ & $\begin{array}{c}\text { Kurtosis } \\
(\mu \mathrm{V})\end{array}$ & $\begin{array}{l}\text { Lin } \\
\text { reg } \\
(\mu V)\end{array}$ & $\begin{array}{c}\text { FFT } \\
\text { Max } \\
\text { Value }\end{array}$ & $\begin{array}{c}\text { FFT } \\
\text { Max } \\
\text { F }\end{array}$ & $\begin{array}{c}\text { PSD } \\
\text { Max } \\
\text { F }\end{array}$ & $\begin{array}{c}\text { PSD } \\
\text { Max } \\
\text { Power }\end{array}$ \\
\hline \multicolumn{11}{|c|}{ Correct calculation of numerical question for Theta, $10 \mathrm{sec}$} \\
\hline 0.0025 & -8.3887 & 8.4343 & 2.3219 & 0.0089 & 4.4417 & 0.0001 & 0.247 & 5.394 & 5.505 & 0.007 \\
\hline \multicolumn{11}{|c|}{ Miscalculation of numerical question for Theta, $10 \mathrm{sec}$} \\
\hline 0.0029 & -6.7304 & 7.3858 & 2.2174 & 0.0697 & 3.3104 & -0.0001 & 0.253 & 5.312 & 4.905 & 0.007 \\
\hline \multicolumn{11}{|c|}{ Correct answer to the verbal question for Theta, $10 \mathrm{sec}$} \\
\hline-0.0092 & -7.5684 & 7.6766 & 2.3793 & -0.0137 & 2.9594 & 0.0019 & 0.275 & 5.15 & 5.252 & 0.009 \\
\hline \multicolumn{11}{|c|}{ Incorrect answer to the verbal question for Theta, $10 \mathrm{sec}$} \\
\hline-0.0009 & -8.0445 & 8.4283 & 2.4155 & 0.0084 & 3.5146 & -0.0024 & 0.273 & 5.549 & 5.227 & 0.008 \\
\hline
\end{tabular}

During numerical correct tasks, mean: $0.0025 \mu \mathrm{V}$, FFT value: $0.247 \mu \mathrm{V}$, FFT max Frequency: $5.394 \mathrm{~Hz}$, PSD max power: $0.007 \mu \mathrm{V}^{2} / \mathrm{Hz}$, PSD max Frequency: $4.905 \mathrm{~Hz}$. When numerical tasks are answered incorrectly, mean: 0.0029, FFT value: 0.253, FFT max Frequency: $5.312 \mathrm{~Hz}$, PSD max power: $0.007 \mu \mathrm{V}^{2} / \mathrm{Hz}$, PSD max Frequency: $4.905 \mathrm{~Hz}$ was found to be. Verbal during correct tasks, mean: $0.0092 \mu \mathrm{V}$, FFT value: $0.275 \mu \mathrm{V}$, FFT max Frequency: $5.150 \mathrm{~Hz}$, PSD max power: $0.009 \mu \mathrm{V}^{2} / \mathrm{Hz}$, PSD max Frequency: $5.252 \mathrm{~Hz}$. When verbal tasks are answered incorrectly, mean: -0.0009, FFT value: 0.273, FFT max Frequency: $5.549 \mathrm{~Hz}$, PSD max power: $0.008 \mu \mathrm{V}^{2} / \mathrm{Hz}$, PSD max Frequency: $5.227 \mathrm{~Hz}$ was found to be.

There was no significant difference between numerical correct calculation and numerical incorrect calculation in all variables ( $p>0.05)$. Similarly, verbal mental tasks were examined and there was no statistically significant difference between right and wrong theta waves in all variables ( $>0.05)$. 
Table 2. Comparison of frequency and power spectral densities obtained from correct and incorrect numerical and verbal responses

\begin{tabular}{|c|c|c|c|}
\hline \multirow{2}{*}{$\begin{array}{l}\text { Parameters } \\
\text { for Theta }\end{array}$} & $\begin{array}{l}\text { Mean } \pm \text { Standart deviation, } \\
\text { Median (25th percentile - } 75 \\
\text { th percentile) }\end{array}$ & $\begin{array}{c}\text { Mean } \pm \text { Standart deviation, } \\
\text { Median ( } 25 \text { th percentile }-75 \\
\text { th percentile) }\end{array}$ & \multirow[t]{2}{*}{$\mathrm{P}$} \\
\hline & $\begin{array}{c}\text { Numerical correct } \\
\text { calculation }\end{array}$ & Numerical miscalculation & \\
\hline FFT Max value $(\mu \mathrm{V})$ & $0.239(0.1720 \sim 0.3020)$ & $0.226(0.2102 \sim 0.2957)$ & 0.538 \\
\hline FFT Max F (Hz) & $5.029(4.3205 \sim 6.6160)$ & $4.931(4.5890 \sim 5.9320)$ & 0.881 \\
\hline PSD Max F (Hz) & $5.058(4.6690 \sim 6.5167)$ & 5.058 (4.669 5.7387) & 0.217 \\
\hline \multirow[t]{2}{*}{ PSD Max Power $\left(\mu V^{2} / H z\right)$} & $0.005(0.0030 \sim 0.0105)$ & $0.005(0.004 \sim 0.0077)$ & 0.867 \\
\hline & $\begin{array}{l}\text { Correct answer to the verbal } \\
\text { question }\end{array}$ & $\begin{array}{l}\text { Incorrect answer to the } \\
\text { verbal question }\end{array}$ & $\mathrm{P}$ \\
\hline FFT Max value $(\mu \mathrm{V})$ & $0.27505 \pm 0.0901$ & $0.27325 \pm 0.0692$ & 0.924 \\
\hline FFT Max F (Hz) & $5.1509 \pm 1.4377$ & $5.5495 \pm 1.1016$ & 0.138 \\
\hline PSD Max F (Hz) & $5.2525 \pm 1.1882$ & $5.2278 \pm 1.3281$ & 0.918 \\
\hline PSD Max Power $\left(\mu \mathrm{V}^{2} / \mathrm{Hz}\right)$ & $0.0065(0.004 \sim 0.0130)$ & $0.0060(0.005 \sim 0.01275)$ & 0.684 \\
\hline
\end{tabular}

$\mathrm{P}>0.05$ was not statistically significant.

\section{Discussion}

In a study conducted by the Jamos et al., in the cognitive performance study of 20 women, it was stated that there was an increase in the relative power of EEG theta waves [8]. The researchers observed an increase in theta activity during memory study and a decrease in the efficiency of the theta wave after memory tasks [9]. As a result of intracranial EEG recording from the hippocampus of 10 epilepsy patients, two different verbal memory tasks were performed, and it was reported to be proportional to theta strength that increased with memory performance by hippocampal stimulation [15]. İshii et al. indicated that theta rhythms increased during focused attention on mental computation [10]. It is stated that the amplitudes of the theta wave are higher during mental arithmetic performance [11]. It was found that there was a power increase in EEG theta bands in short-term memory processing processes on 10 women [12]. In the study conducted on 16 participants, it was stated that there was an increase in frontal theta rhythms during mental arithmetic tasks [13]. In our study, it was observed that theta activity in the numerical tasks with the correct answer decreased compared to the theta activity with the wrong answer. No change in the power spectral densities of those who gave the correct answer and responded incorrectly in numerical tasks was observed. In verbal tasks, an increase in FFT max value and PSD max power was observed in the process of responding correctly, while no significance was observed in FFT and PSD. No significant decrease or increase was observed between FFT and PSD 
parameters ( $p>0.05)$. In our study, there was an increase in average amplitude in the wrong response processes and this was compatible with the literature, but no significant change was observed in the FFT and PSD parameters. It is uncertain that this is related to the excitement of the subjects.

The researchers found an increase in the activity of the EEG theta wave during 4 different mental arithmetic tasks [14]. The researchers received the EEG recording from 17 healthy male participants, and the participants were asked a total of 10 questions, consisting of numerical, visual, and verbal questions with different degrees of difficulty in their favorite music and traffic noise environments. As a result of the study, it was concluded that while solving difficult problems, people are more affected by the environment than solving simple problems [16]. In our study, an increase in mean amplitude was found in both the numerical and verbal processes to respond incorrectly. It was observed that the maximum frequency in the raw EEG record taken from the subjects for the theta wave was in the range of 4-7 Hz. No significant difference was observed in power analysis in numerical and verbal correct and wrong answer tasks. We could not find a statistically significant difference between FFT, PSD, and mean values during numerical and verbal tasks $(p>0.05)$. When we look at our literature and study findings, it can be seen that EEG recording may be affected by environmental conditions and the importance of recording is remarkable.

Our study is thought to contribute to the literature due to the low number of similar studies. In addition, the number of subjects was kept close to the literature studies during the study, but it is a matter of curiosity on how the results may change if the sample volume increases. However, since the working conditions are standard, the work has repeatability. The disadvantage of this study seems to be the extent to which the environmental and subjects' effects are not fully understood. Therefore, more detailed studies are needed with different numerical and verbal tasks. Thus, more studies are needed regarding theta change in fixed EEG recording and how it changes when mental tasks are applied.

\section{Conclusion}

In this study, the activity of the theta wave formed in the brain during the different responses to the same numerical and verbal task was interpreted. Thus, how the brain behaves in the right and wrong answers is still a mystery. It is important that a person responds incorrectly to something right, and the possibility that it can be detected. It is suggested that the new studies should be attentive to the studies by considering the effects such as electrode-induced effects, noises from the devices and subjects, ambient sounds, psychological state, and excitement. Therefore, we could not observe a significant change in the study, but a more detailed analysis is needed for investigating the brain waves generated during these processes.

Ethical Procedure: Kursehir Ahi Evran University Faculty of Medicine Clinical Research Ethics Committee decision was taken (2019-07/85). The experiment was carried out according to the Declaration of Helsinki.

The compliance to Research and Publication Ethics: This work was carried out by obeying research and ethics rules. 


\section{References}

[1] Sammer, G., Blecker, C., Gebhardt, H., Bischoff, M., Stark, R., Morgen, K., \& Vaitl, D. "Relationship between regional hemodynamic activity and simultaneously recorded EEG - theta associated with mental arithmetic - induced workload", Hum Brain Mapp, 28(8), 793-803, 2007.

[2] Amin, H.U., Malik, A.S., Badruddin, N., \& Chooi, W.T. "EEG mean power and complexity analysis during complex mental task", In 2013 ICME International Conference on Complex Medical Engineering, IEEE, 2013, (pp. 648-651). DOI: 10.1109/ICCME.2013.6548329

[3] Butkevičiūtè, E., Bikulčienè, L., Sidekerskienė, T., Blažauskas, T., Maskeliūnas, R., Damaševičius, R., \& Wei, W. "Removal of movement artefact for mobile EEG analysis in sports exercises", IEEE Access, 7, 7206-7217, 2019.

[4] Gong, Y., Xu, S. "Mental state detection in classroom based on EEG brain signals", Nat Sci, 11(11), $315,2019$.

[5] Jensen, O., Tesche, CD. "Frontal theta activity in humans increases with memory load in a working memory task", Eur J Neurosci, 15(8), 1395-1399, 2002.

[6] Ghaderi, A.H., Nazari, M.A., Darooneh, A.H. "Functional brain segregation changes during demanding mathematical task", Int J Neurosci, 129(9), 904-915, 2019.

[7] Biopac MANBSL4., Reference manuals of AcqKnowledge Software Guide and MP System Hardware Guide, BIOPAC Systems Inc., 42 Aero Camino, Goleta, CA -USA., 2019.

[8] Ramos, J., Corsi-Cabrera, M., Guevara, M.A., \& Arce, C. "EEG activity during cognitive performance in women", Int J Neurosci, 69(1-4), 185-195, 1993.

[9] Jensen, O., Tesche, C.D. "Frontal theta activity in humans increase with memory load in a working memory task", Eur J Neurosci, 15(8), 1395-1399, 2002.

[10] Ishii, R., Canuet, L., Ishihara, T., Aoki, Y., Ikeda, S., Hata, M., \& Iwase, M. "Frotal midline theta rhythm and gamma power changes during focused attention on mental calculation: a MEG beamformer analysis", Front Hum Neurosci, 8, 406, 2014.

[11] Klimesch, W. "EEG alpha and theta oscillations reflect cognitive and memory performance: a review and analysis", Brain Res Brain Res Rev, 29, 169-195, 1999.

[12] Schack, B., Vath, N., Petsche, H., Geissler, H.G., \& Möller, E. "Phase-coupling of theta-gamma EEG rhythms during short-term memory processing”, Int J Psychophysiol, 44(2), 143-163, 2002.

[13] Katahira, K., Yamazaki, Y., Yamaoka, C., Ozaki, H., Nakagawa, S., \& Nagata, N. "EEG correlates of the flow state: A combination of increased frontal theta and moderate frontocentral alpha rhythm in the mental arithmetic task", Front Psychol, 9, 300, 2018.

[14] So, WK., Wong, S.W., Mak, J.N., \& Chan, R.H. "An evaluation of mental workload with frontal EEG”, PloS one, 12(4), 2017. e0174949. 10.1371/journal.pone.0174949

[15] Jun, S., Lee, S.A., Kim, J.S., Jeong, W., \& Chung, C.K. "Task-dependent effects of intracranial hippocampal stimulation on human memory and hippocampal theta power", Brain Stimulat, 13(3), 603-613, 2020. 
[16] Eraldemir, S.G., Arslan, M., Yıldırım, E., \& Koc, A.F. "The effect of the environment on brain activity during problem solving", The J Cogn Syst, 4(2), 34-37, 2019 